\title{
Microscopic polyarteritis: a forgotten aetiology of haemoptysis and rapidly progressive glomerulonephritis
}

\author{
Scott Zashin, Ron Fattor, Don Fortin
}

\begin{abstract}
A 76 year old white woman died from massive pulmonary haemorrhage nine days after she was admitted to Parkland Memorial Hospital for evaluation of haemoptysis and rapidly progressive glomerulonephritis. The differential diagnosis of haemoptysis with rapidly progressive glomerulonephritis is presented with particular emphasis on Wegener's granulomatosis and microscopic polyarteritis. Necropsy showed a small vessel necrotising vasculitis associated with a focal segmental necrotising glomerulonephritis consistent with microscopic polyarteritis.
\end{abstract}

\section{Case report}

A 76 year old white woman was admitted to the hospital for evaluation of fevers, patchy pulmonary infiltrates, and worsening renal function; she expired on the ninth hospital day.

She had been well until two months before admission to a hospital in Beaumont, Texas with fevers to $38.9^{\circ} \mathrm{C}$, haemoptysis, oral ulcers, epistaxis, nasal congestion, and dyspnoea. The admission chest $x$ ray showed a right upper lobe posterior segment cavitary infiltrate. Treatment was started with cefuroxime and she was treated parenterally for 10 days. Her sputum culture grew Klebsiella pneumoniae. The following evaluation was made: white blood cells $16 \cdot 9-25 \cdot 0 \times$ $10^{9} / 1$ with $12-15 \%$ eosinophils, packed cell volume $0 \cdot 3$, platelets $613 \times 10^{9} / 1$, urine analysissp gr $1 \cdot 005$, pH $6 \cdot 5$, no protein, $2+$ blood with two to seven red blood cells/high powered field, creatinine $53-133 \mu \mathrm{mol} / 1$, protein $71 \mathrm{~g} / 1$, albumin $35 \mathrm{~g} / \mathrm{l}$, serum aspartate transaminase $38 \mathrm{IU} / \mathrm{l}$, alkaline phosphatase $275 \mathrm{IU} / 1, \mathrm{CH}_{50}$ normal, antinuclear antibody titre $1 / 80$, thyroid function tests normal, erythrocyte sedimentation rate $115 \mathrm{~mm} / \mathrm{h}$. A chest computed tomographic scan was performed showing patchy ill defined confluent infiltrative changes in both mid and upper lung fields.

Bronchoscopy was performed on 26 August 1987, which showed mild interstitial fibrosis and chronic inflammation. The bronchial washings were negative for malignant cells. Multiple acid fast smears were negative.

Her fever subsequently defervesced and she remained afebrile for $\mathbf{4 8}$ hours. Her discharge chest $x$ ray showed no change in infiltrates. She presented at follow up on 22 September 1987 with complaints of fevers for 14 days, with dependent left lower extremity oedema and arthralgias. She was transferred to this hospital for further evaluation.

Drugs on admission included famotidine and a stool softener. She denied smoking or alcohol intake. Her physical examination at the time of admission on 8 October 1987 was normal except for multiple purpuric maculae, petechial lesions around paronychiae of fingers and plantar aspects of feet. Her chest $x$ ray showed a right middle lobe opacity silhouetting the right heart. Laboratory test results included creatinine 513 $\mu \mathrm{mol} / \mathrm{l}$, protein $59 \mathrm{~g} / \mathrm{l}$, albumin $28 \mathrm{~g} / \mathrm{l}$, white blood cells $21 \times 10^{9} / 1$ with $90 \%$ platelets, $6 \%$ lymphocytes, $3 \%$ monocytes, $1 \%$ eosinophils, packed cell volume $0 \cdot 3$, urine analysis_red blood cells too numerous to count, many white blood cells, white blood cell cast with $2+$ protein.

At the time of admission three sets of blood cultures were drawn, which returned growing Staphylococcus epidermidis in one of six bottles. Biopsy of the purpuric lesions showed 'leucocytoclastic vasculitis'. On the third hospital day she received a bolus of $1.8 \mathrm{~g}$ methylprednisolone sodium succinate as she continued to show a rising creatinine concentration (now $539 \mu \mathrm{mol} / \mathrm{l}$ ) with a persistent active sediment. Other laboratory results returned at that time were rheumatoid factor $85.9 \mathrm{IU} / \mathrm{ml}, \mathrm{C} 4186 \mathrm{mg} / \mathrm{l}, \mathrm{C} 3 \mathrm{l} .02 \mathrm{~g} / \mathrm{l}$, antinuclear antibody test negative, erythrocyte sedimentation rate $98 \mathrm{~mm} / \mathrm{h}$, total serum iron $220 \mu \mathrm{g} / \mathrm{l}$, total iron binding capacity $1.63 \mathrm{mg} / \mathrm{l}$, hepatitis B surface antigen non-reactive. A renal biopsy performed on 13 October 1987 showed that two of six glomeruli seen were crescents. The immunofluorescence showed deposits of IgG, IgM, and C3. She then received cyclophosphamide $100 \mathrm{mg}$ and prednisolone $120 \mathrm{mg}$ both by mouth every day beginning 15 October 1987. She remained stable until $4 \mathrm{pm}$ on the 16 October 1987 when she was found to have haemoptysis, measured as $1 / 2$ cup. Her examination showed marked tachypnoea (respiratory rate $40 / \mathrm{min}$ ). An arterial blood gas obtained while the patient was receiving 2 litres of oxygen by nasal cannula showed $\mathrm{pH} 7 \cdot 27, \mathrm{PCO}_{2}, 5 \cdot 5$ $\mathrm{kPa}, \mathrm{Po}_{2} 6.2 \mathrm{kPa}$, which improved with $100 \%$ oxygen supplementation by Venturi mask to $\mathrm{pH}$ $7 \cdot 22, \mathrm{PCO}_{2} 6.4 \mathrm{kPa}, \mathrm{Po}_{2} 8 \cdot 7 \mathrm{kPa}$. She was intubated and underwent emergency fibreoptic bronchoscopy. The bleeding source was felt to be the right upper lobe, but blood was present in all airways. During the bronchoscopy she developed massive haemoptysis and became asystolic. Cardiopulmonary resuscitation was started, but she died.

A postmortem examination was performed.

\section{Necropsy}

Principal necropsy findings in this patient involved the lungs and kidney. 
LUNGS

Gross examination of the lungs showed intense congestion of all lobes. Examination of the lung at high magnification showed focal areas of alveolar wall thickening with associated necrosis and acute inflammation. All the pulmonary vessels were reviewed. A rare, degenerating vessel could be identified in such areas, although owing to disruption, it was not possible to determine whether the vessel was a vein or an artery. One or two of these necrotic areas were present in each lung section. There was no evidence of a granulomatous process. Special stains (tissue Gram stain and Gomori's methenamine silver, with verified positive controls) were performed for bacterial and fungal micro-organisms; both of these stains were negative.

\section{KIDNEYS}

The most notable finding in the cortex was seen in the residual fraction of non-sclerotic glomeruli. Approximately $90 \%$ of all these glomeruli showed a global and segmental necrotising and proliferative glomerulitis. Occasional crescents were seen, though most glomeruli were remarkable only for the necrotising proliferative glomerulitis. Immunofluorescence studies on the renal biopsy specimen obtained before death showed only minimal granular deposits of IgG. There was no evidence of IgA. The tubules of both kidneys showed mild focal dilatation.

DIAGNOSIS

Microscopic polyarteritis.

\section{Discussion}

The differential diagnosis in this patient with haemoptysis and rapidly progressive glomerulonephritis is long (table 1). Yet the most likely diagnosis was either Wegener's granulomatosis or microscopic polyarteritis.

Wegener's granulomatosis is characterised by glomerulonephritis and by a necrotising granulomatous vasculitis of the upper and lower respiratory tract. Fauci and his group at the NIH have accumulated a large series of patients. In their prospective study of 85 patients there was a $1 \cdot 6 / 1$ male to female ratio, the mean age of

Table 1: Differential diagnosis of rapidly progressive glomerulonephritis and haemoptysis

Infection
Bacterial endocarditis
Legionnaires' disease $^{1}$
Streptococcal pneumonia
Bronchogenic carcinoma ${ }^{2}$
Systemic lupus erythematosus ${ }^{3}$
Goodpasture's syndrome
Idiopathic rapidly progressive glomerulonephritis
without immune complexes)
Vasculith and
Classic polyarteritis nodosa
Wegener's granulomatosis
Microscopic polyarteritis
Hypersensitivity vasculitis
Schönlein-Henoch purpura
Mixed cryoglobulinaemia ${ }^{11}$

disease onset was 40 with a range of 14-75 years, and the mean duration from the time of symptoms to presentation was $8 \cdot 3$ months. ${ }^{12}$

The most common presenting complaint was sinusitis with severe rhinorrhoea or nasal obstruction (57/85). Otitis, secondary to obstruction of the eustachian tubes, was also common (21/85). Epistaxis was seen in only $9 / 85$ of patients.

Pulmonary complaints were prevalent. Chest radiographs showed $60 / 85$ presenting with an infiltrate, some with cavitation. The characteristic nodules of Wegener's granulomatosis with or without cavitation were seen less frequently. ${ }^{1213}$ It should be noted, however, that radiographic abnormalities may occasionally be fleeting. ${ }^{14}$ Haemoptysis was seen in only $15 / 85$ of patients. ${ }^{12}$ Yet, in a series of patients with Wegener's granulomatosis at Hammersmith Hospital haemoptysis was apparent in 21/53 of patients, with a high mortality $(5 / 53)$ in the first two weeks. ${ }^{15}$ Thus the low incidence of haemoptysis in the NIH group may be due to the reasons for which their patients were referred.

Skin lesions were uncommon on initial presentation, but typical ulcerative or papular lesions were present in more than 38/45 of patients at some time in their course ${ }^{12}$; leucocytoclastic vasculitis was unusual.

Laboratory investigation shows that the erythrocyte sedimentation rate is characteristically very high. A normochromic/normocytic anaemia and leucocytosis are also common. Renal abnormalities include increased plasma creatinine, haematuria, and, less frequently, red cell casts. Rheumatoid factor was measured in 44 patients and was positive in $27 . .^{12} 1416$

Although granulomatosus necrotising vasculitis can be seen in biopsy specimens of the skin, sinus, or kidney, the lung has the greatest yield. ${ }^{17}$ Biopsy of a lesion in the nasopharynx can often provide a diagnosis if an adequate specimen consisting of deep tissue, and not just superficial necrotic tissue, is obtained.

Renal biopsy specimens are most commonly characterised by a focal segmental necrotising glomerulonephritis. ${ }^{18}$ Crescent formation is seen during rapidly progressive renal failure. Findings showing extraglomerular necrotising vasculitis are rare. ${ }^{17}$ Although the clinical presentation of our patient is compatible with Wegener's granulomatosis, the diagnosis was microscopic polyarteritis.

Published work on microscopic polyarteritis is scarce and confusing because it is commonly included in series of hypersensitivity vasculitis and sometimes in series of classic polyarteritis. The term microscopic polyarteritis is best used to describe a patient with evidence of a small vessel vasculitis associated with a rapidly progressive glomerulonephritis clinically and a focal segmental necrotising glomerulonephritis pathologically. Excluded are patients with other diseases associated with a small vessel vasculitis and necrotising glomerulonephritis (Wegener's granulomatosis, Schönlein-Henoch purpura, mixed cryoglobulinaemia, hypocomplementaemic vasculitis, and hypersensitivity vasculitis secondary to neoplasm). ${ }^{9}$

The Hammersmith group recently published 
a large series describing patients who fit the diagnosis of microscopic polyarteritis. ${ }^{9}$ The patient profile of this group is similar to the profile of those afflicted with Wegener's granulomatosis. Of the 34 patients in the series, two out of three were male. All but two were white. The average age was 50 years with a range of 14-73. The mean duration from the time of symptoms to presentation was 3.7 months.

The onset of disease is often preceded by constitutional symptoms. Purpura was commonly present and biopsy of skin lesions showed predominantly leucocytoclastic vasculitis.

Pulmonary manifestations were dominated by haemoptysis and alveolar haemorrhage as defined by a typical alveolar infiltrate and a raised transfer factor of the lung for carbon monoxide (TLCO). TLCO is the diffusion capacity corrected for the alveolar volume. ${ }^{19} \mathrm{~A}$ raised value is felt to be a sensitive indicator of alveolar haemorrhage. Pulmonary infiltrates without infection were not seen.

Nasopharyngeal involvement was common and included oral ulcers, sinusitis, and epistaxis. Abdominal involvement was also common, though this was not present in our patient. Finally, cardiovascular and neurological abnormalities were rare.

The laboratory investigations of all patients showed a raised erythrocyte sedimentation rate, anaemia, an abnormal creatinine concentration, and microscopic haematuria. Most had granular or red cell casts. Other significant laboratory results included a high prevalence of leucocytosis with neutrophilia and thrombocytosis. Rheumatoid factor was positive in $41 \%$.

If renal studies are excluded most of these laboratory abnormalities are non-specific and found to a greater or lesser extent in all types of vasculitis. An exciting, prospective controlled study recently published in the Lancet showed that autoantibodies against neutrophil cytoplasmic antigens were specific and sensitive for both Wegener's granulomatosis and microscopic polyarteritis. ${ }^{20}$ Controls were normal patients and those with pulmonary-renal syndromes. Nevertheless, more patients need to be studied before this test can be used as an important diagnostic aid in clinical medicine.

Renal biopsy specimens were obtained from $94 \%$ of patients. A focal segmental necrotising glomerulonephritis was found in all patients. ${ }^{9}$ Crescents were seen in $88 \%$.

Yet, we are told that no evidence of a focal segmental necrotising glomerulonephritis was found in our patient. Because $100 \%$ of patients with microscopic polyarteritis in a previous study had this finding it might be thought that microscopic polyarteritis could be excluded as a diagnosis. The renal biopsy specimen was inadequate, however, as only six glomeruli were seen. Thus the characteristic lesion was not evident until necropsy.

Direct immunofluorescence staining was performed on biopsy specimens of 20 patients with microscopic polyarteritis and showed minimal deposition of $\mathrm{C} 3$ and even less deposition of IgG. ${ }^{9}$ This lack of significant immunofluorescence is consistent with all types of vasculitides, excluding Schönlein-Henoch purpura.
An open lung biopsy would probably be necessary to distinguish Wegener's granulomatosis from microscopic polyarteritis, however. Still, the distinction between these two entities was only of academic importance as the major consideration was treatment of rapidly progressive glomerulonephritis.

Although no controlled trials have been done, the standard treatment of systemic necrotising vasculitis with internal organ involvement is with a combination of cyclophosphamide and prednisone. ${ }^{8}$ The cyclophosphamide should be given in a dose of $1 \cdot 5-2 \mathrm{mg} / \mathrm{kg}$ daily by mouth. If there is fulminant disease a dose of up to $4 \mathrm{mg} / \mathrm{kg}$ daily can be given for the first three days and then cut back to $2 \mathrm{mg}$ daily. If the patient cannot tolerate drugs by mouth or there is intestinal involvement, the drug is given intravenously. The dose may be increased by 25 mg every two weeks until a clinical response occurs or toxicity develops. The drug should be continued for one year after a remission has occurred. The goal of therapy is to suppress disease activity while keeping the white blood cell count above $3.5 \times 10^{9} / 1$ to decrease the risk of infection.

Azathioprine is an alternative agent, but in the NIH experience it is less effective than cyclophosphamide. ${ }^{21}$ Still, it may be useful in patients who cannot tolerate the side effects of cyclophosphamide, such as leucopenia, haemorrhagic cystitis, or gonadal dysfunction. Both drugs take at least 10 days before any effect on disease activity is seen. Consequently, prednisone is added for immediate antiinflammatory and immunosuppressive effects. The recommended dose is $1-2 \mathrm{mg} / \mathrm{kg}$ daily in three to four divided doses. The divided dose early in treatment produces the maximum therapeutic response as the effect of prednisone is at a peak after four hours. After two weeks of continuous treatment the drug can be given as a single morning dose and withdrawn over three months.

Pulse therapy-that is, $1-2 \mathrm{~g}$ of methylprednisolone given intravenously over 30 minutes-is often used in severe cases of vasculitis. Although there are no data at present showing a benefit over high dose prednisone taken by mouth, it is reasonable to use this regimen in disease not responding to conventional steroid doses or in life threatening disease.

In addition to treating the kidney disease, high dose prednisone and pulse therapy have been successfully used to treat pulmonary haemorrhage. 2223

The combination of cyclophosphamide and prednisone has been very effective in treating Wegener's granulomatosis. Before this treatment the average one year survival was less than $20 \%$ with a mean of five months. ${ }^{24}$ With the aforementioned regimen $93 \%$ of patients experience a remission with a four year survival of $88 \% .^{12}$

Less success has been obtained in microscopic polyarteritis. The five year actuarial survival was $65 \%$ in the Hammersmith study. ${ }^{9}$ At the NIH the increased mortality compared with that for patients with Wegener's granulomatosis might have been secondary to the 
Table 2: Summary

\begin{tabular}{lll}
\hline $\begin{array}{l}\text { Clinical } \\
\text { finding }\end{array}$ & $\begin{array}{l}\text { Wegener's } \\
\text { granulomatosis }\end{array}$ & $\begin{array}{l}\text { Microscopic } \\
\text { polyarteritis }\end{array}$ \\
\hline $\begin{array}{lll}\text { Rapidly progressive } \\
\text { glomerulonephritis }\end{array}$ & ++ & ++++ \\
$\begin{array}{l}\text { Haemoptysis } \\
\text { Constitutional symptoms }\end{array}$ & +++ & +++ \\
$\begin{array}{l}\text { Nasopharyngeal involvement } \\
\text { Leucocytoclastic vasculitis }\end{array}$ & +++ & ++++ \\
$\begin{array}{l}\text { Pulmonary infiltrates/nodules } \\
\text { (excluding infection and }\end{array}$ & + & ++ \\
haemorrhage) & ++ & ++ \\
\hline
\end{tabular}

inherent diseases because azathioprine and not cyclophosphamide was used as the principal mode of treatment, or might have been due to the patient population.

Patients with microscopic polyarteritis and pulmonary haemorrhage had a poor prognosis. Of the 10 patients with this complication, three died in the first two weeks. These deaths represented $60 \%$ of the deaths during this period. Because pulmonary haemorrhage is an indicator of such a poor prognosis it is doubtful that any alteration in treatment would have changed the eventual outcome of this case.

In summary, the presentation of this patient is consistent with both Wegener's granulomatosis and microscopic polyarteritis (table 2). In addition to their association with rapidly progressive glomerulonephritis and haemoptysis, both present with constitutional symptoms and nasopharyngeal involvement. Yet, because of the presence of leucocytoclastic vasculitis, a common finding in microscopic polyarteritis, and the absence in our patient on presentation to Parkland of radiographic findings consistent with Wegener's granulomatosis, microscopic polyarteritis represented the best clinical diagnosis. This diagnosis was confirmed by pathological evidence of a focal and segmental necrotising glomerulonephritis, a small vessel vasculitis, and the absence of granulomas.

1 Kirby B D, Snyder K M, Mever R D, Finegold S M Legionnaires disease: report of sixty-five nosocomiall acquired cases and review of the literature. Medicine (Baltimore) 1980; 59: 188-205.

2 Whitworth J A, Morel-Maroger L, Mignon F, Richet G. The significance of extracapillary proliferation: clinicopathological review of 60 patients. Nephron 1976; 16: 1-19.

3 Cush J J, Goldings E A. Drug induced lupus. Am $\mathcal{F}$ Med Sci 1985; 290: 36-45.

4 Buffaloe G N, Evans J E, McIntosh R M, Glassock R J, Tavel $T$ B, Terman D S. Antibodies to human glomerular basement membrane: modified methodology for detection in human serum. Clin Exp Immunol 1980; 39: 136-40.

5 Wilson C B, Dixon F J. Anti-glomerular basement membrane antibodv-induced glomerulonephritis. Kidney Int 1973; 3: antibody-

6 Beirne G J, Wagnild J P, Zimmerman S W, Macken P D, Burkholder P M. Idiopathic crescentic glomerulonephritis. Medicine (Baltimore) 1977; 56: 349-81

7 Beirne G J, Kopp W L, Zimmerman S W. Goodpasture's syndrome. Dissociation from antibodies to glomerular basement membrane. Arch Intern Med 1973; 132: 261-3.

8 Fauci A S, Haynes B F, Katz P. The spectrum of vasculitis. Clinical pathologic, immunologic and therapeutic considerations. Ann Intern Med 1978; 89: 660-76.

9 Savage C O, Winearls C G, Evans D J, Rees A J, Lockwood

C M. Microscopic polyarteritis: presentation, pathology and prognosis. $Q \mathcal{F}$ Med 1985; 56: 467-83.

10 Cream J J, Gumpel J M, Peachey R D. Schönlein-Henoch purpura in the adult. A study of 77 adults with anaphylactoid or Schönlein-Henoch purpura. Q $\mathcal{F}$ Med 1970; 39: 461-84

11 Martinez J S, Kohler P F. Variant "Goodpasture's syndrome" The need for immunologic criteria in rapidly progressive glomerulonephritis and hemorrhagic pneumonitis. Ann Intern Med 1971; 75: 67-76.

12 Fauci A S, Haynes B F, Katz P, Wolff S M. Wegener's granulomatosis: prospective clinical and therapeutic experience with 85 patients for 21 vears. Ann Intern Med 1983; 98 76-85.

13 Flye $M$ W, Mundinger G H Jr, Fauci A S. Diagnostic and therapeutic aspects of the surgical approach to Wegener's granulomatosis. 7 Thorac Cardiovasc Surg 1979; 77: 331-7.

14 Fauci A S, Wolff S M. Wegener's granulomatosis. Studies in eighteen patients and a review of the literature. Medicine (Baltimore) 1973; 52: 535-61

15 Haworth S J, Savage C O, Carr D, Hughes J M B, Rees A J Pulmonary haemorrhage complicating Wegener's granulomatosis and microscopic polvarteritis. Br Med f 1985; 290 $1775-8$

16 Wolff S M, Fauci A S, Horn R G, Dale D C. Wegener's granulomatosis. Ann Intern Med 1974; 81: 513-25.

17 Cupps T R, Fauci A S. Wegener's granulomatosis. In: Smith L, ed. The vasculitides. Philadelphia: Saunders, 1981: 83.

18 Godman G C, Churg J. Wegener's granulomatosis. Patholog rodman $\mathrm{GC}$, Churg J. Wegener's granulomatosis. Pathology and review.

19 Ewan P N, Jones H A, Rhodes C G, Hughes J M B Detection of intrapulmonary haemorrhage with carbon monoxide uptake. $N$ Engl 7 Med 1976; 295: 1391-6.

20 Savage C S, Jones S, Winearls C G, Marshall P D, Lockwood $C M$. Prospective study of radioimmunoassay for antibodies against neutrophil cytoplasm in diagnosis of systemic vasculitis. Lancet 1987 ; i: 1389-93.

21 Fauci A S, Katz P, Haynes B F, Wolff S M. Cyclophosphamide therapy of severe systemic necrotizing vasculitis. $N$ Engl f Med 1979; 301: 235-8.

22 Briggs W A, Johnson J P, Teichman S, Yeager H C, Wilson C B. Antiglomerular basement membrane antibody mediated glomerulonephritis and Goodpasture's synmediated glomerulonephritis and Goodpas

23 Leatherman J N, Davies S F, Hoidal J R. Alveola hemorrhage syndrome: diffuse microvascular lung hemorrhage in immune and idiopathic disorders. Medicine (Baltimore) 1984; 63: 343-61.

24 Walton E W. Giant-cell granuloma of the respiratory tract. (Wegener's granulomatosis). Br Med f 1958; ii: 265-70. 